\title{
Perspectives on Positive Academic Ethics: an Introduction
}

\author{
Diane Pecorari ${ }^{1} \cdot$ Wendy Sutherland-Smith ${ }^{2}$
}

Published online: 8 October 2021

(C) The Author(s), under exclusive licence to Springer Nature B.V. 2021

Integrity and misconduct are two sides of the same coin. Acts of misconduct violate principles of integrity, so promoting integrity implies an interest in combatting acts which challenge and degrade it. There is ample evidence that scholarly institutions and bodies interested in integrity frequently shift their gaze to its converse. For instance, the International Center for Academic Integrity (ICAI) defines academic integrity with respect to positive principles, establishing "six fundamental values: honesty, trust, fairness, respect, responsibility, and courage" (2021, p. 4). Despite this focus on the positive, in a reading list published by the ICAI listing key articles in academic integrity (Bertram Gallant, 2012), misconduct leaves a discernable footprint. Of 42 articles, 13 include "cheat" or "cheating" in their titles, six "plagiarism," and 12 "dishonesty" (by contrast, a single article has the word "honesty" in its title). Only nine of the 42 have titles which avoid mention of some negative act. Similarly, a search of the table of contents of the Journal of Academic Ethics finds 20 articles mentioning "plagiarism" in the title, and six naming the relatively recent phenomenon of contract cheating. Sixteen titles include "dishonesty" but only two include the word "honesty."

Therefore, we ask, has the shift to "positive integrity" in the written discourses of institutions been mirrored in practice? Have we really moved to actioning and implementing "positive" rather than "negative" integrity frames? While recognising that it is appropriate and indeed necessary to investigate the transgressive, the objective of this Special Issue is to consider whether the balance is right, or whether greater awareness and implementation of positive ethics can create positive integrity change. What would happen if we were aspirational and kept the question "How can we do better?" front of mind?

We acknowledge that transgressive acts are worthy of attention by virtue of their ability to threaten positive virtues. This gives positive virtues a very real primacy in principle (if not always respected in practice). The ICAI explains the need to emphasise positive values like this:

Many instructors, students, staff, and administrators embrace the principles of academic integrity because they know the goals of teaching, learning, research, and service can only be accomplished in ethical environments. Despite that, scholarly institutions rarely identify and describe their commitment to the principles of integrity

Diane Pecorari

diane.pecorari@cityu.edu.hk

1 City University of Hong Kong, Kowloon Tong, Hong Kong, China

2 Deakin University, Geelong, Australia 
in positive and practical terms. Instead, they tend to address academic integrity by identifying and prohibiting behaviors that run counter to the principles of integrity. By articulating the fundamental values of academic integrity, ICAI attempts to frame academic integrity in ways that are both positive and pragmatic. (2021, p. 4)

The first four articles in the Special Issue consider broad areas in which organisations may reimagine their commitment to positive ethics in their tenets and operations. The first proposes a rethinking of institutional ethos to reflect notions of solidarity in the material life of the academy. The second explores the issue of improving working conditions and a sense of belonging for adjunct/sessional staff in the lived experience of institutional life. The third investigates ways in which institutions may review their recognition and reward for high publication rates, which currently allow for exploitation by predatory conferences. The final article examines the history of discourse in research on academic integrity and ways in which positive research integrity may be foregrounded.

Jolante Bieliauskaitè's article, titled "Solidarity in academia and its relationship to academic integrity," uses the lenses of philosophy and sociology to explore the principle of "solidarity" in the academy as a cornerstone of ethics and integrity. The principle of solidarity encompasses positive notions of co-operation between groups or individuals at different levels of the academy, albeit noting the "dark side" of this principle. The author explains the conceptual connection between solidarity, ethics and integrity and concludes that "academic solidarity and academic integrity are linked through a social ethos that maintains socially significant values." She argues that solidarity should be reflected in the ethos, structures, codes and regulations of the academy and realised in the embodied lives of institutions.

Congruent with the theme of solidarity and ethics in action, Cecile Sam explores how the "solidarity between tenure lined and non-tenure lined faculty" can build an academic community founded on ethics of care. In "How academic community and an ethic of care can shape adjunct work environments: A case study of a community college" she investigates ways in which one institution has improved the lived experience of adjunct/sessional staff through "work behavior, decision-making and policies." A positive sense of membership and belonging encourages a "sense of responsibility" within the overall community and negates more divisive notions of "academic community," which include some staff while excluding others. She concludes that positive ethics provides a useful framework that both "faculty and administrators used to base their decisions and policy rationale" upon.

Diane Pecorari's article, "Predatory conferences: What are the signs?" explores the issue of choice in conference support and attendance. She identifies and analyses key features of predatory conferences to better inform the academic community about their nature. The author also provides a tool for "scientific literacy by mapping the characteristics which can reliably differentiate between the legitimate and the predatory" in conference selection. From a positive ethics perspective, individual and institutional decisions on conference attendance or publication are moved from the "unethical" to the "virtuous end of the cline." This positive change may assist institutions, academics and research students make "ethically appropriate choices" about the conferences they support and attend.

Thomas Lancaster investigates the history of discourse in the academic integrity field in "Academic dishonesty or academic integrity? Using Natural Language Processing (NLP) techniques to investigate positive integrity in academic integrity research." He analyses data from paper titles written in academic integrity between 1904 and 2019. Whilst establishing three main categories (academic integrity, academic dishonesty and plagiarism detection), he discusses the variations in negative, neutral and positive discourses. He 
notes a recent trend "has been a move towards neutral integrity" in paper title choice, with higher readerships for negative rather than positive titles. However, the ten most prolific academic integrity researchers defy this trend and employ positive terms which, he hopes, may inspire emerging researchers to adopt a positive ethics approach.

The next three articles in this Issue explore ways in which various stakeholders in the academy may focus more on the negative infractions against principles of integrity rather than positive underpinning values. They thereby highlight what we consider to be a missed opportunity to reimagine positive ethics in action, and one already noted in the area of psychology (e.g., Aoyagi \& Portenga, 2010). Handelsman et al. (2002) discuss the ways in which a fixation on the transgressive promotes an unhelpful narrowing of perspectives which may cause the foundational concepts of positive ethics to be overshadowed (e.g., "seminars on academic ethics degenerate into discussions of student cheating," p. 732).

Rebecca Moore Howard and Sandra Jamieson explore the narrowing of perspectives alluded to by Handelsman et al. by describing pedagogies which focus on the positive rather than the transgressive. In their article "The ethics of teaching rhetorical intertextuality" the authors discuss the rhetorical intertextuality approach, which focuses on engaging students in dialogue with texts and their sources. In so doing, they contend, discourses that focus on the transgressive are rendered irrelevant, as the process views students as "authors rather than transgressors" of conventions. Rhetorical intertextuality, they argue, embodies positive ethics as students develop understanding and meaning of the target text in a process of "collaboration with source texts." The authors advocate that this is a positive approach to student meaning-making.

In a similar vein, Jess Gregory advocates "establishing a consensus of correct behavior in addition to ensuring consent" between academic stakeholders. In her article titled "Plagiarism as a social contract: A new way to approach plagiarism," she cites research that places plagiarism as transgressive behaviour requiring interventionist or, occasionally, positive teaching approaches for its remediation. The author then applies Integrative Social Contract Theory (ISCT), which derives from business ethics in the area of ethical decisionmaking, to explore twenty years of abstracts to ascertain if such consensus between parties is apparent. She suggests ways in which consensual social contracts may be better achieved in the future and concludes positive ethics is enhanced by applying ISCT as "authors will have meaningfully consented to abide by the shared norms of correct behavior; respecting intellectual property."

Some psychology researchers have noted that adopting a remedial approach to ethics (i.e., an orientation toward the minimum acceptable standards) reflects an "incomplete" view of ethics (Knapp \& VandeCreek, 2006). They argue that "most psychologists want to do more than just avoid being punished; they want to have a positive impact on others and to excel in their profession" (p. 4). The impetus to go beyond a remedial approach and adopt a positive ethics framework has been advocated in other fields, such as science and engineering education (Han, 2015) as well as business (Sekerka et al., 2014). Handelsman et al. advocate a positive ethics approach, the objectives of which are:

to shift the ethics of psychologists from an almost exclusive focus on wrongdoing and disciplinary responses to a more balanced and integrative approach that includes encouraging psychologists to aspire to their highest ethical potential. (2002, p. 731)

Among Handelsman et al.'s recommendations is unequivocal education or training for the field, "mak[ing] an affirmative effort to teach ethical sensitivity" (Handelsman et al., 2002, p. 741). Kathryn Strong Hansen in "Optimistic fiction as a tool for ethical reflection in STEM" supports the view of explicit ethics education. She argues that to "encourage 
the replication of ethical behavior," there needs to be a focus on "exemplary ethical behavior" in the role models presented to students. Utilising optimistic science fiction texts, the author explores how students are encouraged to think and reflect in ethically constructive ways. She contends that the six domains of Fiction for Specific Purposes provide positive notions of hope and creativity inherent in many science fiction texts as they focus on the aspirational, model ethical ideals and norms through positive integrity. Combined with the benefit of no real-life risk for students in terms of positing incorrect solutions and valuable ethical reflection opportunities, the author argues, students learn to "cultivate a sense of ethicality being possible and laudatory" in their various professions.

This diverse collection of research articles demonstrates that a positive ethics framework is timely and suggests ways that it could be discussed, explored and actioned. The articles illustrate the shift in focus which is implied by adopting a positive ethics research perspective. From such a perspective, the question the academy and its members must ask themselves is no longer "Is this good enough?" but "Is this the best it can be?" The latter question is harder to answer. The ambition of this Special Issue is to suggest that this question should be asked more often, by more people and organisations and in more settings.

\section{References}

Aoyagi, M. W., \& Portenga, S. T. (2010). The role of positive ethics and virtues in the context of sport and performance psychology service delivery. Professional Psychology: Research and Practice, 41, 253-259. https://doi.org/10.1037/a0019483

Bertram Gallant, T. (Ed.). (2012). Twenty years of academic integrity: Top articles and book chapters 19922012. Clemson, SC: International Center for Academic Integrity.

Han, H. (2015). Virtue ethics, positive psychology, and a new model of science and engineering ethics education. Science and Engineering Ethics, 21, 441-460. https://doi.org/10.1007/s11948-014-9539-7

Handelsman, M. M., Knapp, S., \& Gottlieb, M. C. (2002). Positive ethics. In C. R. Snyder \& S. J. Lopez (Eds.), Handbook of positive psychology (pp. 731-744). Oxford University Press.

International Center for Academic Integrity (ICAI). https://academicintegrity.org. Accessed 8 July 2021.

Knapp, S. J., \& VandeCreek, L. D. (2006). Remedial and positive ethics. In S. J. Knapp \& L. D. VandeCreek (Eds.), Practical ethics for psychologists: A positive approach (pp. 3-14). American Psychological Association.

Sekerka, L. E., Comer, D. R., \& Godwin, L. N. (2014). Positive organizational ethics: Cultivating and sustaining moral performance. Journal of Business Ethics, 119, 435-444. https://doi.org/10.1007/ s10551-013-1911-z

Publisher's Note Springer Nature remains neutral with regard to jurisdictional claims in published maps and institutional affiliations. 